\title{
Influence of Silver Contents on the Tribological Properties of Ni-Based Self-Lubricating Coatings by Atmospheric Plasma Spraying
}

\author{
Bo $\mathrm{Li}^{1,2} \cdot$ Jun-Hong $\mathrm{Jia}^{1} \cdot$ Yi-Min $\mathrm{Gao}^{2} \cdot$ Hong-Jian Guo ${ }^{1} \cdot$ Min-Min Han ${ }^{1} \cdot$ Wen-Zhen Wang ${ }^{1}$
}

Received: 28 October 2016/Revised: 21 February 2017/Published online: 6 April 2017

(C) The Chinese Society for Metals and Springer-Verlag Berlin Heidelberg 2017

\begin{abstract}
The NiCrAlY-Mo-Ag composite coatings were prepared by atmospheric plasma spraying. The tribological properties of the composite coatings were investigated from 25 to $900{ }^{\circ} \mathrm{C}$ in details. The tribo-layer formed on the worn surface of the composite coatings and influenced the tribological properties at different temperatures. The addition of silver could effectively decrease the friction coefficient and wear rate of the coatings at the wide range of temperature. The rubbing process could form the nickel molybdate and promote the formation of silver molybdate within the worn surfaces at high temperature. The synergistic lubricating effects of nickel molybdate and silver molybdate are attributed to the improvement of the tribological properties of coatings at high temperature.
\end{abstract}

KEY WORDS: Plasma spraying; Tribological properties; Synergistic lubricating; High temperature

\section{Introduction}

$M \operatorname{CrAlY}(M=\mathrm{Co}$ or/and Ni) coatings prepared by thermal spraying technique have been diffusely used in the industries of nuclear power, aerospace and automotive owing to the excellent high-temperature corrosion and oxidation resistance and it could withstand the high thermal and mechanical loads due to possessing excellent high-temperature self-lubricating properties [1-6]. Graphite and molybdenum disulfide usually acted as solid lubricants

Available online at http://link.springer.com/journal/40195.

Jun-Hong Jia

jhjia@licp.cas.cn

$\triangle$ Yi-Min Gao

ymgao@mail.xjtu.edu.cn

1 State Key Laboratory of Solid Lubrication, Lanzhou Institute of Chemical Physics, Chinese Academy of Sciences, Lanzhou 730000, China

2 State Key Laboratory for Mechanical Behaviour of Materials, School of Materials Science and Engineering, Xi' an Jiaotong University, Xi' an 710049, China could improve the tribological properties of the composites [7-15]. But this kind of solid lubricants would be oxidized or decomposed above $500{ }^{\circ} \mathrm{C}$, and therefore lose their lubricating effects [16]. Silver could decrease the wear rate and friction coefficient of the composites and provide the excellent lubricating effect below $400{ }^{\circ} \mathrm{C}$ due to a low shear strength and large diffusion coefficient on the worn surfaces during the sliding process [16-21]. An et al. [19] prepared the NiMoAl- $\mathrm{Cr}_{3} \mathrm{C}_{2}-\mathrm{Ag}$ composite coatings by high-velocity oxy-fuel (HVOF) and demonstrated that the incorporation of silver could efficiently improve the tribological properties of the composite coatings. Our previous studies showed that increasing the silver contents could decrease the wear rate and friction coefficient of the composites by power metallurgical sintered [16]. In recent years, due to excellent lubrication performance in wide temperature range, Ag-Mo dual-lubricant has been investigated by several researchers [22-25]. Chen et al. fabricated the NiCrAlY-Ag-Mo composite coatings by atmospheric plasma spraying (APS), which possesses excellent tribological properties at the wide range of temperature [25], but there are few studies on the influence of 
the silver contents on the mechanical properties and tribological properties of the coatings.

In the present work, we investigated the microstructure, tribological and mechanical properties of NiCrAlY-AgMo composite coatings with different mass fractions of silver prepared by APS at a wide temperature range. The tribological properties of composite coatings were researched from room temperature (RT) to $900{ }^{\circ} \mathrm{C}$. In the meantime, the silver molybdate and nickel molybdate tribo-chemical reaction films formed on worn surface and their influences on the tribological properties of composite coatings were discussed.

\section{Experimental}

\subsection{Preparation of Composite Coatings}

The NiCrAlY-Mo-Ag composite coatings with different silver contents were fabricated by APS. The NiAl powder was applied as bond coat. Commercially, available feedstock powders of Ni22Cr10Al1.0Y, Mo and NiAl were gained from Sulzer Metco. The powder of Ag was obtained from Beijing Research Institute of Mining and Metallurgy. The Inconel 718 alloys acted as the substrate and were cleaned by ultrasonic cleaner with acetone after sandblasted. The compositions of each composite coating are listed in Table 1. The main spraying parameters employed were: $\mathrm{H}_{2}$ flow rate, $5 \mathrm{~L} / \mathrm{min}$; Ar flow rate, $40 \mathrm{~L} / \mathrm{min}$; power feed rate, $42 \mathrm{~g} / \mathrm{min}$; voltage, $55 \mathrm{~V}$; current, $500 \mathrm{~A}$.

\subsection{Characterization}

The microhardness was measured by using a MH-5-VM microhardness tester with a normal load of $300 \mathrm{~g}$ and a dwell time of $5 \mathrm{~s}$. The measurement was at least ten times on each sample. The adhesive strength of the composite coating was measured in conformity to the standard of ASTM C633. The specimen diameter was $25.4 \mathrm{~mm}$, and the tensile rate was $0.5 \mathrm{~mm} / \mathrm{min}$. Scanning electron microscopy (SEM) was used to observe the microstructures of composite coatings. The X-ray diffraction (XRD) was used to determine the phase composition and structures of

Table 1 Composition of the coatings

\begin{tabular}{lccc}
\hline Composite coatings & NiCrAlY (wt\%) & Mo (wt\%) & Ag (wt\%) \\
\hline NMA & 100 & 0 & 0 \\
NMA0 & 90 & 10 & 0 \\
NMA1 & 80 & 10 & 10 \\
NMA2 & 75 & 10 & 15 \\
NMA3 & 70 & 10 & 20 \\
\hline
\end{tabular}

composite coatings. The micro-Raman was used to research the phase compositions of worn surfaces of composite coatings. The processes of friction and wear tests have been described in detail elsewhere [6].

\section{Results and Discussion}

\subsection{Microstructure of the Coatings}

Figure 1 shows the morphologies of feedstock powders of NiCrAlY, Ag, Mo and NiAl. It can be clearly seen that all feedstock powders have the similar size and very excellent spherical shape. The feedstock powders are mixed uniformly and insure the good flow ability, which is useful to the stability of powder feed rate $[6,25]$.

The XRD patterns of composite coatings with different mass fractions of silver are presented in Fig. 2. It is obvious that the components of composite coatings and feedstock powders have an excellent accordance, and the $\mathrm{Ni}_{3} \mathrm{Al}$ (JCPDS file No. 09-0097) phase is the main phase in all coatings. The diffraction peaks of the single-phase Mo (JCPDS file No. 42-1120) and Ag (JCPDS file No. 04-0783) exist in composite coatings, which indicates that the Mo and $\mathrm{Ag}$ cannot be alloyed in NiCrAlY during thermal spray process. The diffraction peaks of $\mathrm{Y}_{2} \mathrm{O}_{3}$ (JCPDS file No. 43-1036) are identified in all composite coatings. The $\mathrm{Y}_{2} \mathrm{O}_{3}$ phase is an oxide dispersion strengthening phase which can improve the strength of the composite coatings [6].

Figure 3 shows the microstructures of polished cross section of composite coatings. It has the NiAl bond coat between the substrate and coating, in addition, they adhere well. It can be observed in Fig. 3a that the NiCrAlY coating contains many cracks and pores, which shows the existence of typical lamellar structure. We can find from Fig. $3 b$ that the NiCrAlY-Mo-Ag composite coating mainly consists of white $\mathrm{Ag}$ phase, gray Mo phase and dark gray NiCrAlY phase. These components are all metallic in nature which is disadvantageous to the adhesive strength of composite coatings [25]. It can be obviously seen that the three components distribute equably and combine with each other tightly without any evident cracks at the interface of any two phases.

\subsection{Mechanical Properties of the Coatings}

Table 2 shows the microhardness of the composite coatings with different mass fractions of silver. The microhardness of NMA0 coating is higher than that of NMA coating. Addition of Mo could improve the microhardness of the composite coatings. Nevertheless, addition of $\mathrm{Ag}$ deteriorates the microhardness of composite coatings. 

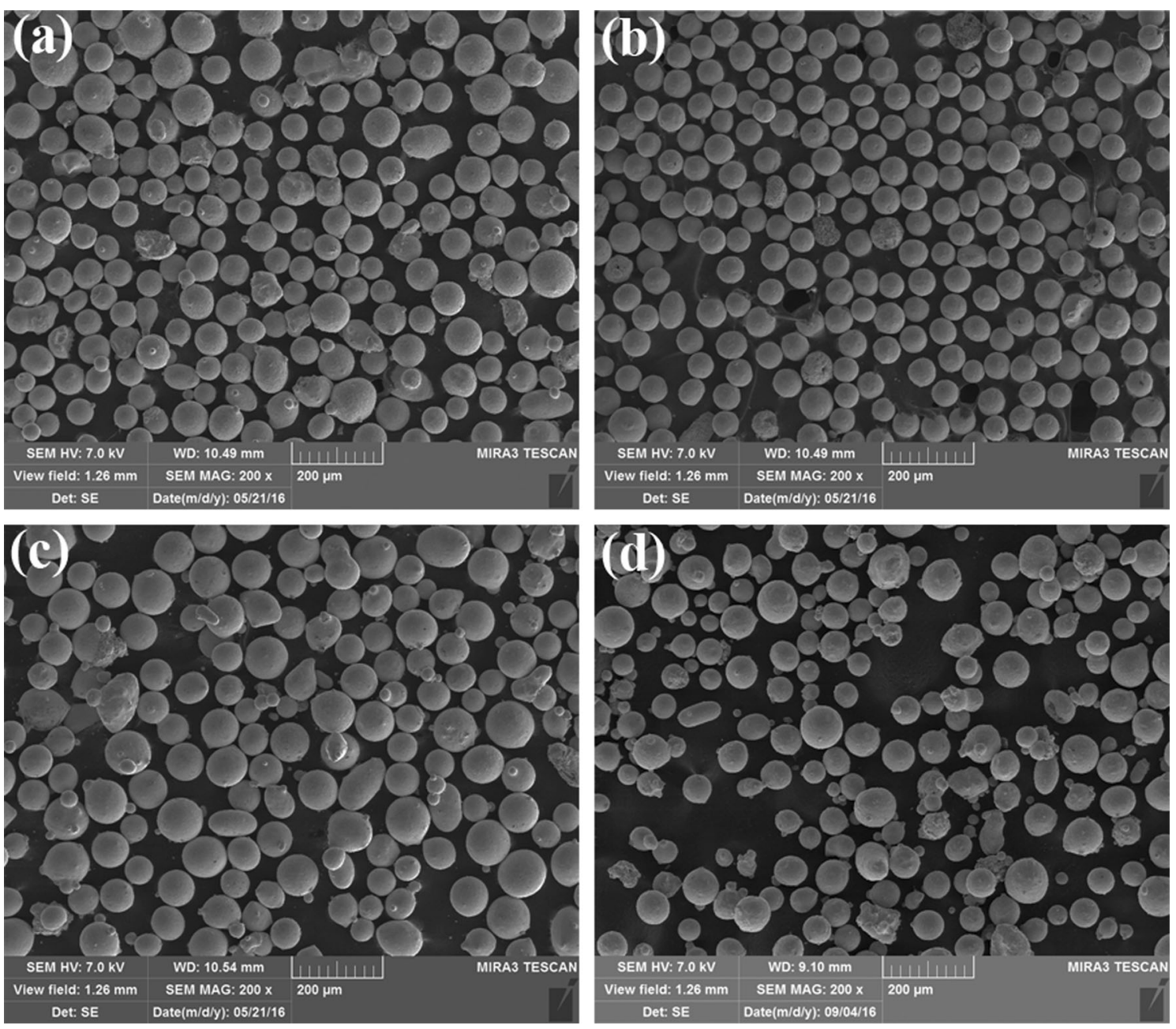

Fig. 1 SEM images of NiCrAlY a, Mo b, Ag c, NiAl d

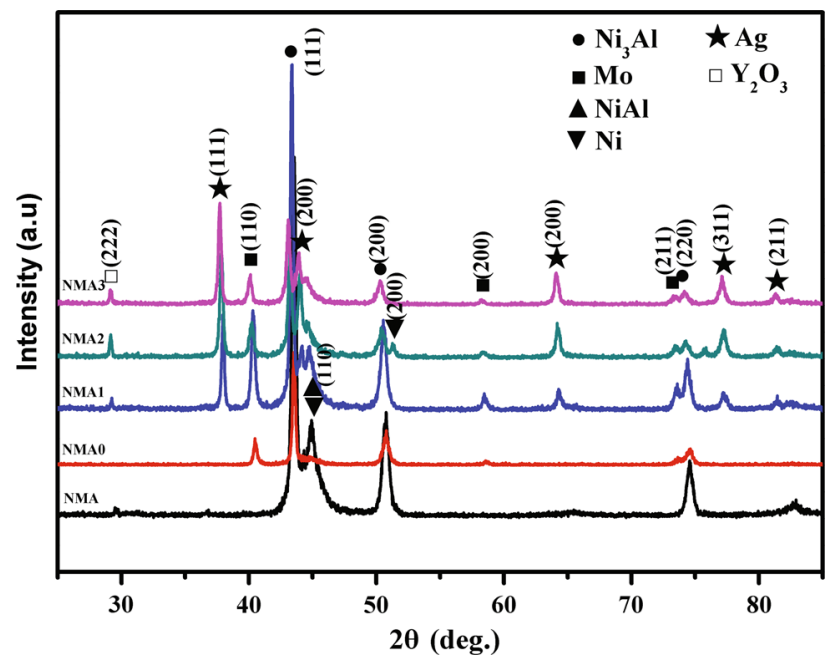

The adhesive strength is an important performance for plasma-sprayed coatings. In order to enhance the adhesive strength of composite coatings, the $\mathrm{NiAl}$ is used to the bond coating. It can be obviously seen that the NiAl bond coating adheres well with substrate and coating (Fig. 3) which could effectively enhance the adhesive strength of coatings. Figure 4 displays the adhesive strength of composite coatings with different mass fractions of silver. And with increasing $\mathrm{Ag}$ content, the adhesive strength of composite coatings is deteriorated. For the plasma-sprayed coatings, the adhesive strength between the substrate and bond coating often exceeds the adhesion of the coating itself and the adhesion between the epoxy and coating [26]. The detachments occur in the interior of NMA0, NMA1, NMA2 and NMA3 coatings, while for the NMA coating, the detachment occurs at the interface between the bond coating and substrate. It is because that the NiCrAlY, Mo and $\mathrm{Ag}$ are all metallic in nature in the composite coatings, which could obviously deteriorate the adhesive strength of composite coatings [25]. 

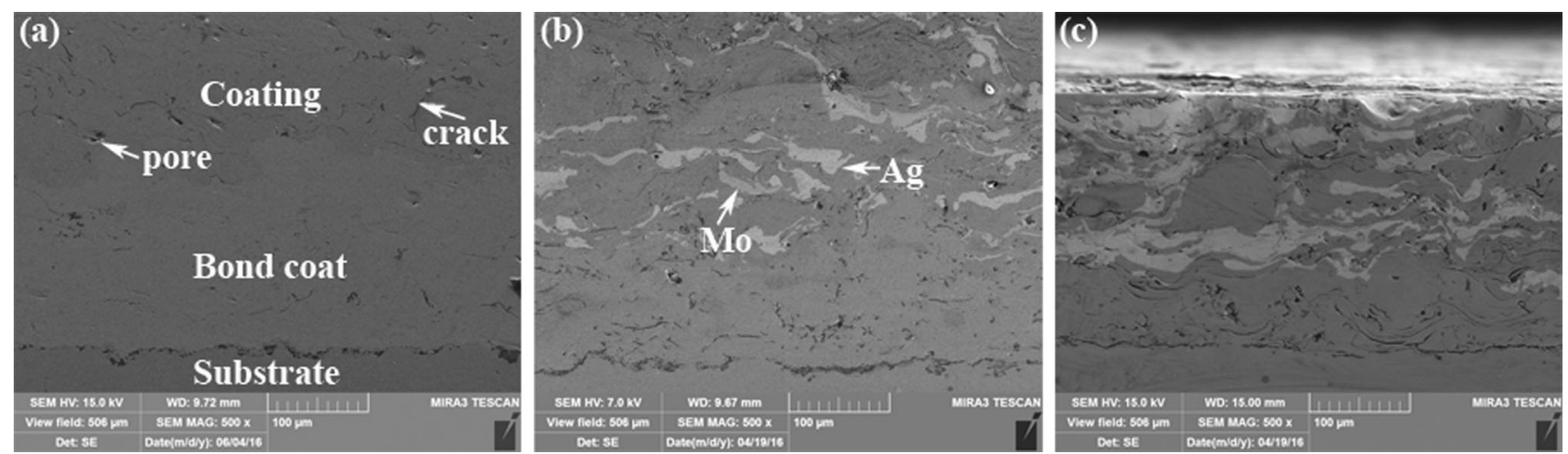

Fig. 3 Micrographs of polished cross section of NMA a, NMA1 b, NMA3 c coatings

Table 2 Vickers hardness of the composite coatings

\begin{tabular}{llllll}
\hline Composite coatings & NMA & NMA0 & NMA1 & NMA2 & NMA3 \\
\hline Vickers hardness (HV) & $329.8 \pm 31.6$ & $342.5 \pm 34.5$ & $297.4 \pm 30.2$ & $273.9 \pm 28.6$ & $241.1 \pm 23.9$ \\
\hline
\end{tabular}

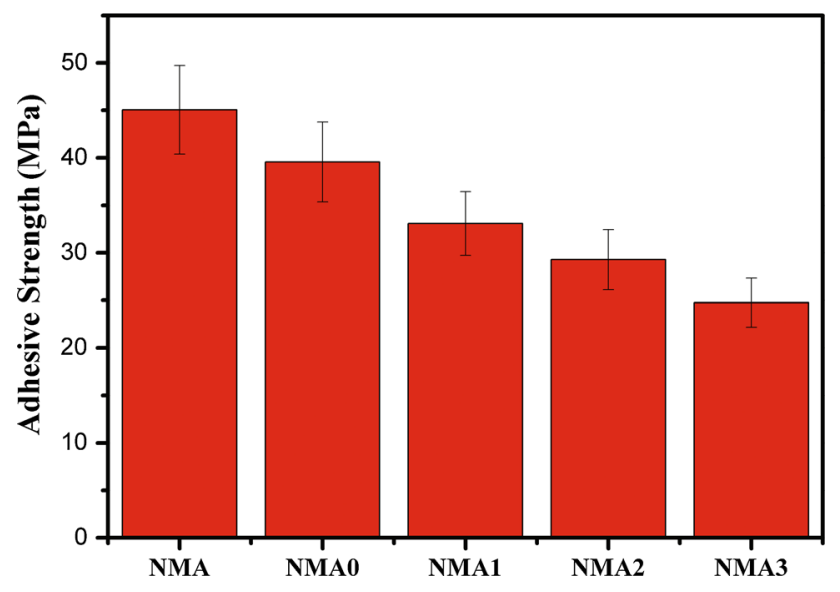

Fig. 4 Adhesive strength of the composite coatings

\subsection{Tribological Properties of Composite Coatings}

Figure 5 presents the friction coefficients of composite coatings with different mass fractions of silver from RT to $900{ }^{\circ} \mathrm{C}$. The NMA coating shows higher friction coefficient than NMA0, NMA1, NMA2 and NMA3 composite coatings at all test temperature except RT. The friction coefficient of NMA1 coating is higher than those of NMA and NMA0 coatings. It may be because that the melt of silver during the thermal spray process makes the residual silver not enough to play the lubricating role. The friction coefficients of all composite coatings reduce continuously with increasing temperature except NMA2 and NMA3 composite coatings at $500{ }^{\circ} \mathrm{C}$. At RT and $300{ }^{\circ} \mathrm{C}$, the NMA3 exhibits the lowest friction coefficient. Nevertheless, the NMA2 and NMA3 coatings exhibit similar friction

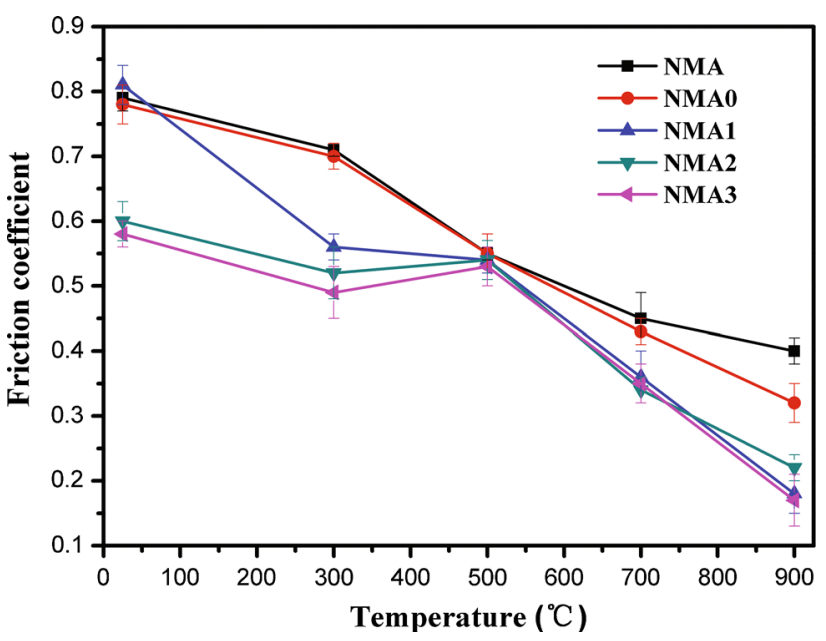

Fig. 5 Friction coefficients of the composite coatings at different test temperatures

coefficient as NMA coating at $500{ }^{\circ} \mathrm{C}$. This may be because that the silver will be softened and loses its lubricating effects at $500{ }^{\circ} \mathrm{C}[19,22]$. At 700 and $900{ }^{\circ} \mathrm{C}$, the friction coefficients of NMA1, NMA2 and NMA3 composite coatings are lower than those of NMA and NMA0 coatings. It illustrates that the addition of silver could obviously decrease the friction coefficients of composite coatings at the wide range of temperature. It is seen distinctly that the NMA3 exhibits lower friction coefficient than any other composite coatings at the wide range of temperature.

Figure 6 shows the wear rates of composite coatings with different mass fractions of silver from RT to $900{ }^{\circ} \mathrm{C}$. The wear rates of all coatings obviously decrease from RT 
to $300{ }^{\circ} \mathrm{C}$. The wear rates of NMA1, NMA2 and NMA3 coatings increase obviously at $900{ }^{\circ} \mathrm{C}$. It is probably because that the worn surfaces of coatings have severe plastic deformation at $900{ }^{\circ} \mathrm{C}[6]$. The NMA1, NMA2 and NMA3 composite coatings show lower wear rate than those of NMA and NMA0 coatings at all test temperatures. The NMA3 composite coating presents the lowest wear rate at RT and $300{ }^{\circ} \mathrm{C}$. This implies that the addition of silver could obviously improve the tribological properties of composite coatings at low temperature.

The SEM micrographs of worn surfaces of composite coatings at different test temperatures are presented in Fig. 7. At RT, for the NMA0 coating (Fig. 7a), the worn surface shows a severe brittle fracture compared with those in NMA1 (Fig. 7e) and NMA3 (Fig. 7i), corresponding to the higher friction coefficient (Fig. 5) and wear rate (Fig. 6). Therefore, the wear mechanism is dominated by abrasive wear. When adding the silver, the worn surface of NMA3 is covered with fine detachments. On account of the smoothest worn surface at RT, the friction coefficient (Fig. 5) and wear rate (Fig. 6) of the NMA3 composite coating are the lowest. At $300{ }^{\circ} \mathrm{C}$, the worn surfaces of all coatings become smoother than those at RT. So the friction coefficient (Fig. 5) and wear rate (Fig. 6) of all coatings are lower than those at RT. At $500{ }^{\circ} \mathrm{C}$, the worn surfaces of all coatings show continuous glaze film with some detachment smears. The worn surfaces of NMA1 (Fig. 7g) and NMA3 (Fig. 7k) coatings show the severe brittle fracture and surface deformation than those at $300{ }^{\circ} \mathrm{C}$. So the friction coefficient (Fig. 5) and wear rate (Fig. 6) of NMA1 and NMA3 are increased from 300 to $500{ }^{\circ} \mathrm{C}$. At $900{ }^{\circ} \mathrm{C}$, the worn surfaces of NMA1 (Fig. 7h) and NMA3 (Fig. 7l) composite coatings form some high-temperature lubricating films. The lubricating films are composed of silver molybdate, nickel molybdate and $\mathrm{NiO}$ shown in Figs. 8 and

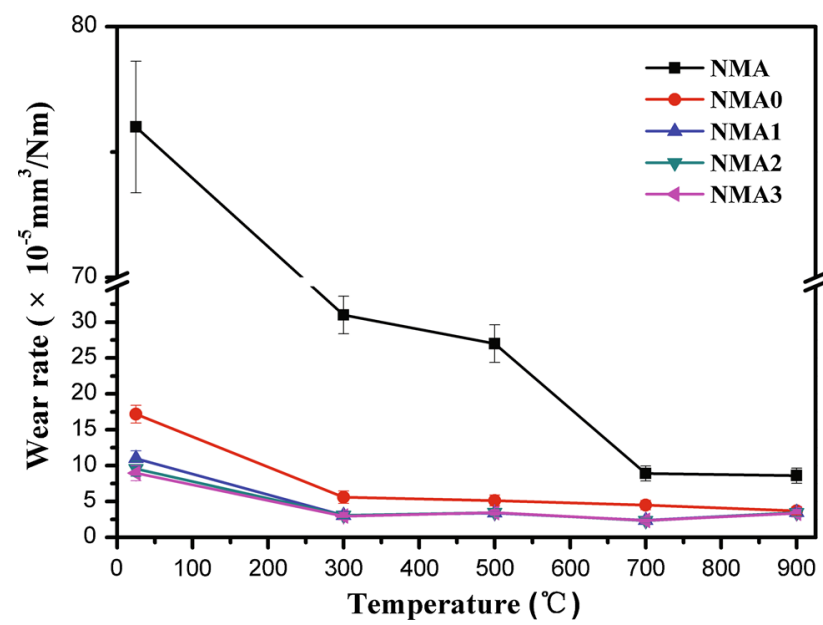

Fig. 6 Wear rates of the composite coatings at different test temperatures
10. The worn surface of NMA0 coating (Fig. 7d) has the obvious delamination. The wear mechanism of coating is characterized by microfractures.

Figure 8 shows the XRD patterns of worn surfaces of NMA3 composite coatings at different temperatures. It can be obviously seen that the diffraction peaks of composite coating after friction test at $300{ }^{\circ} \mathrm{C}$ are nearly the same as that at RT. It clearly illustrates that the components of the composite coating have no obvious change between at RM and $300{ }^{\circ} \mathrm{C}$. Interestingly, the new peaks of silver molybdate can be detected when test runs at $700{ }^{\circ} \mathrm{C}$. At the same time, the diffraction peaks of Mo (JCPDS file No. 42-1120) disappear and Ag (JCPDS file No. 04-0783) peaks weaken. Sliding test after $700{ }^{\circ} \mathrm{C}$, molybdenum and silver can react and form silver molybdate which could effectively decrease the friction coefficient and wear rate of composite coatings at high temperature [16]. Except as the silver molybdate, the diffraction peaks of $\mathrm{NiO}$ (JCPDS file No. 47-1049), $\mathrm{Cr}_{2} \mathrm{O}_{3}$ (JCPDS file No. 04-0787) and $\mathrm{CrO}_{2}(-$ JCPDS file No. 09-0332) appear on the worn surface of coating. It has been approved that the $\mathrm{CrO}_{2}, \mathrm{Cr}_{2} \mathrm{O}_{3}$ and $\mathrm{NiO}$ could also enhance tribological properties of composite coatings at high temperature $[6,14,16,25]$. So the composite coating has lower friction coefficient (Fig. 5) and wear rate (Fig. 6). At $900{ }^{\circ} \mathrm{C}$, the $\mathrm{Ag}_{2} \mathrm{O}$ (JCPDS file No. 19-1155) peaks appear on the worn surface of composite coating. Although the $\mathrm{CrO}_{2}, \mathrm{Cr}_{2} \mathrm{O}_{3}$ and $\mathrm{NiO}$ are well lubricant phases at high temperature and can improve the tribological properties of composite coatings, the worn surface has the severe plastic deformation (Fig. 7), which increases wear rate (Fig. 6) of composite coating at $900{ }^{\circ} \mathrm{C}$ [6].

In order to further determine the tribo-chemical changes of composite coatings at high temperature, the micro-Raman spectra of NMA1 and NMA3 composite coatings are presented in Figs. 9 and 10. For the NAM1 coating, it can be clearly seen that the silver molybdate and nickel molybdate peaks were detected inside the wear track area after 700 and $900{ }^{\circ} \mathrm{C}$, which are ascribed to the $\mathrm{Ag}_{2} \mathrm{MoO}_{4}$, $\mathrm{Ag}_{2} \mathrm{Mo}_{4} \mathrm{O}_{13}, \mathrm{Ag}_{2} \mathrm{Mo}_{2} \mathrm{O}_{7}$ and $\mathrm{NiMoO}_{4}$ peaks. In contrast, there are no silver molybdate and nickel molybdate peaks outside the worn surface (Fig. 9). For the NAM3 coating, the micro-Raman spectra obtained within the worn surface are similar to the NMA1 coating at $700{ }^{\circ} \mathrm{C}$. However, it has the $\mathrm{Ag}_{2} \mathrm{MoO}_{4}$ peak outside the worn surface (Fig. 10a). At $900{ }^{\circ} \mathrm{C}$, the micro-Raman spectra obtained on the worn surface are similar to that obtained outside the worn surface, which consist of $\mathrm{Ag}_{2} \mathrm{MoO}_{4}$ and nickel molybdate peaks. It can be clearly understood that the rubbing process could form the nickel molybdate and thus promote the formation of the silver molybdate on the worn surface at high temperature. When adding the silver, the $\mathrm{Ag}_{2} \mathrm{MoO}_{4}$ is determined outside the worn surface of composite coatings, 

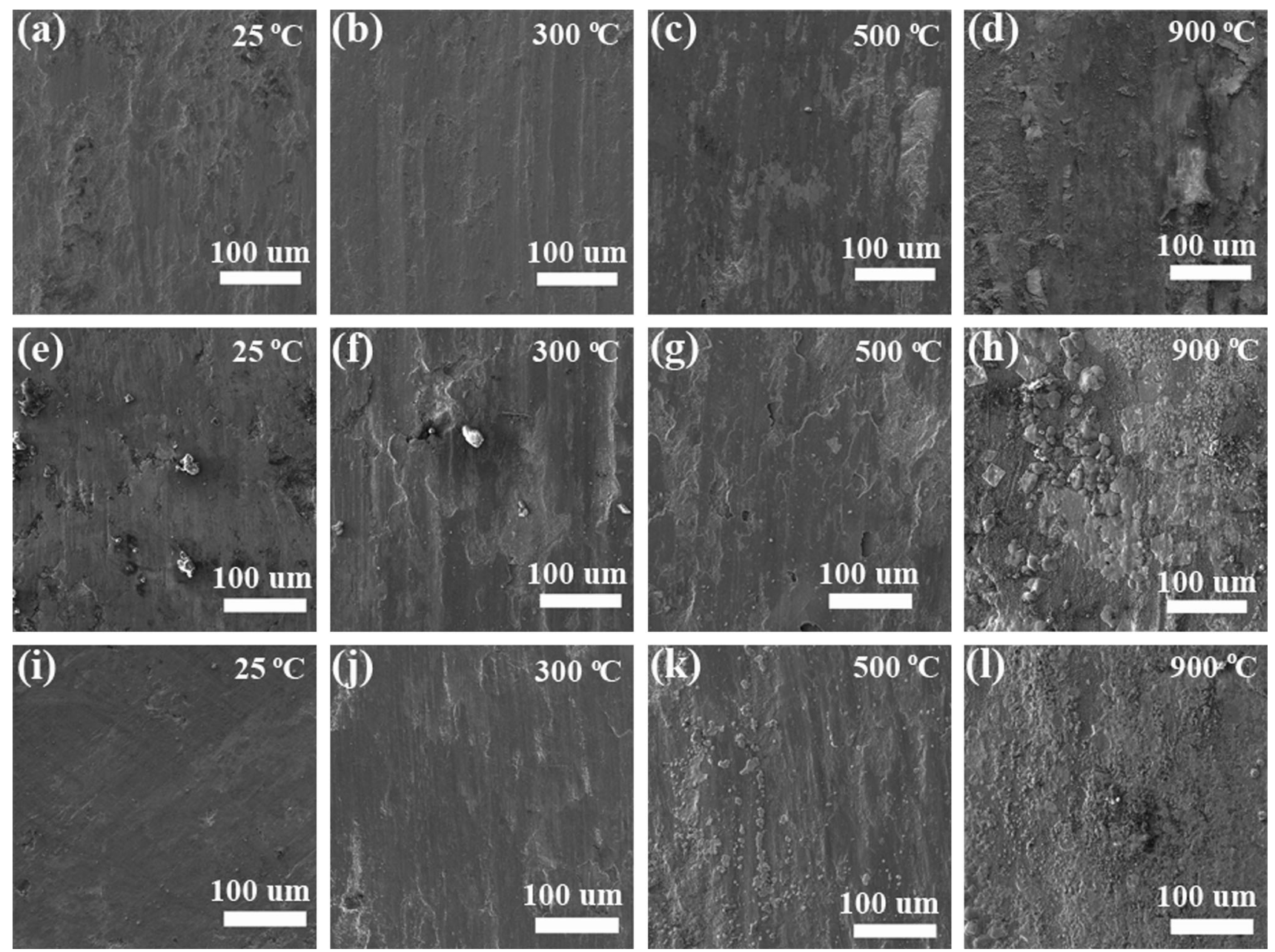

Fig. 7 SEM images of worn surfaces of composite coatings: a-d NMA0 coating, e-h NMA1 coating, i-l NMA3 coating

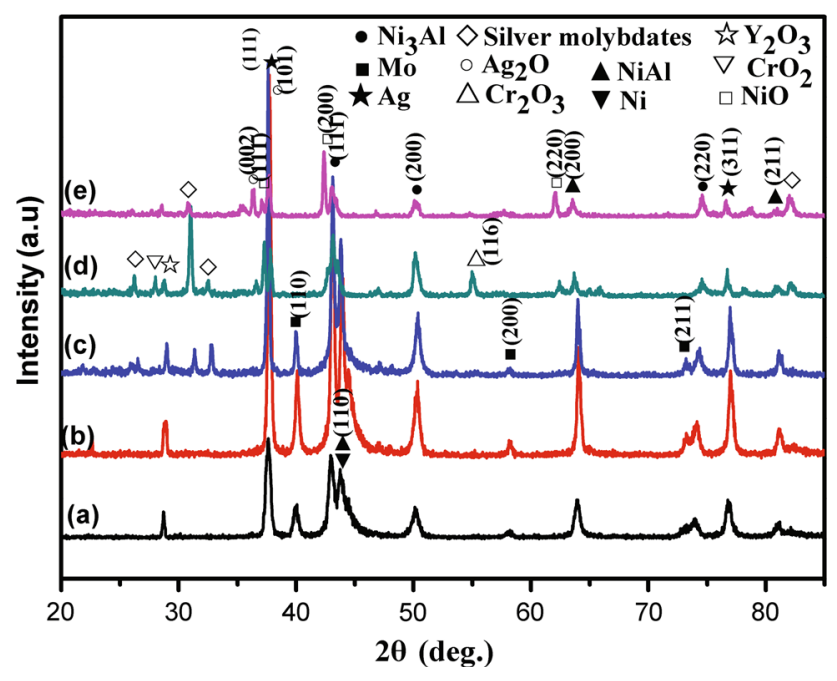

Fig. 8 XRD patterns of worn surfaces of NMA3 composite coating at different temperatures: a $25{ }^{\circ} \mathrm{C}$, b $300{ }^{\circ} \mathrm{C}$, c $500{ }^{\circ} \mathrm{C}$, d $700{ }^{\circ} \mathrm{C}$, e $900{ }^{\circ} \mathrm{C}$ which could effectively improve the tribological properties of composite coatings and has the better lubricating performance than $\mathrm{Ag}_{2} \mathrm{Mo}_{4} \mathrm{O}_{13}$ and $\mathrm{Ag}_{2} \mathrm{Mo}_{2} \mathrm{O}_{7}$ at high temperature $[14,16]$. So the NMA3 coating has the better tribological properties than NMA1 at high temperature.

The structural changes on the worn surface of NMA3 composite coating at different temperatures are evaluated by micro-Raman spectra, as shown in Fig. 11. Raman spectra show the lubricating action and mechanism at different temperatures. From RT to $500{ }^{\circ} \mathrm{C}$, the $\mathrm{Ag}_{2} \mathrm{MoO}_{4}$ peak was detected on the rubbing surface. The $\mathrm{Ag}_{2} \mathrm{MoO}_{4}$ could act as a thermal chemically stable solid lubricant at moderate and high temperatures [27]. So the NMA3 coating possesses the better tribological properties than NMA1 coating at low temperature. While at $700{ }^{\circ} \mathrm{C}$, the peaks of $\mathrm{Ag}_{2} \mathrm{MoO}_{4}, \mathrm{Ag}_{2} \mathrm{Mo}_{4} \mathrm{O}_{13}, \mathrm{Ag}_{2} \mathrm{Mo}_{2} \mathrm{O}_{7}$ and $\mathrm{NiMoO}_{4}$ appear on the worn surface. It can be clearly illustrated that the tribochemical reaction occur on the worn surface and form the silver molybdate and nickel molybdate lubricating composite layer during the sliding process at high temperature. 

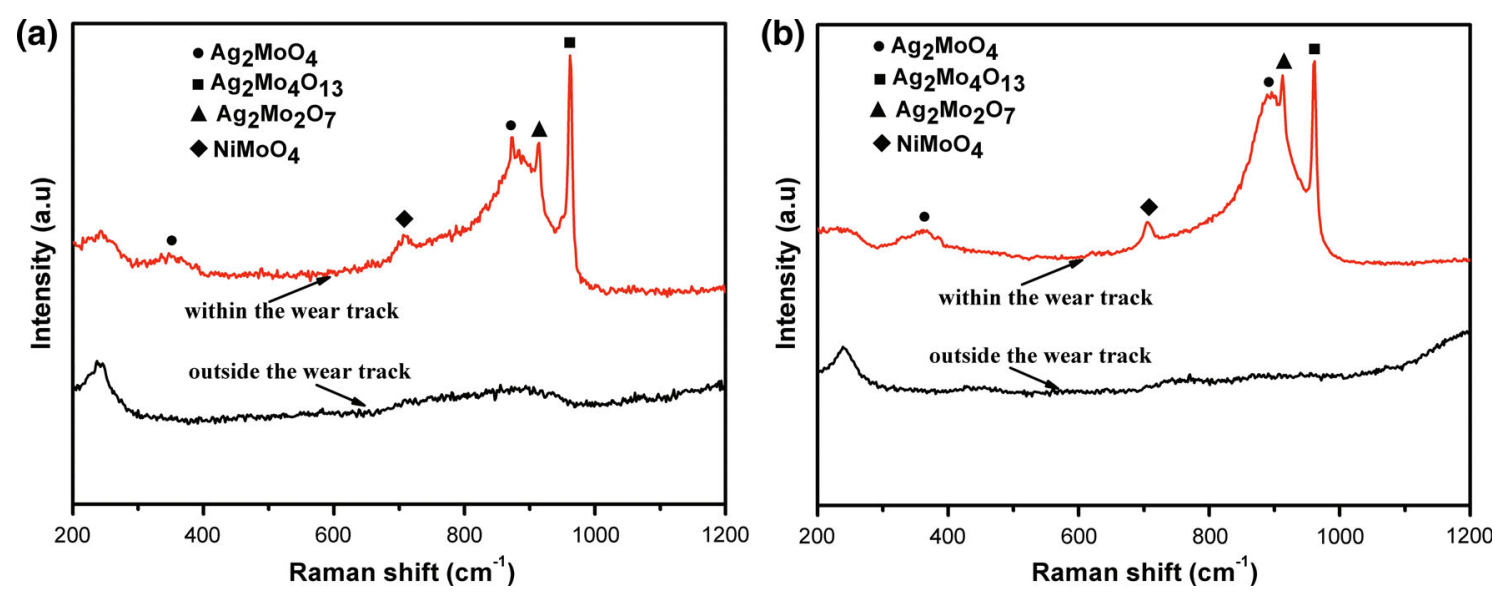

Fig. 9 Micro-Raman spectra of worn surfaces of NMA1 composite coatings tested at a $700{ }^{\circ} \mathrm{C}, \mathbf{b} 900{ }^{\circ} \mathrm{C}$
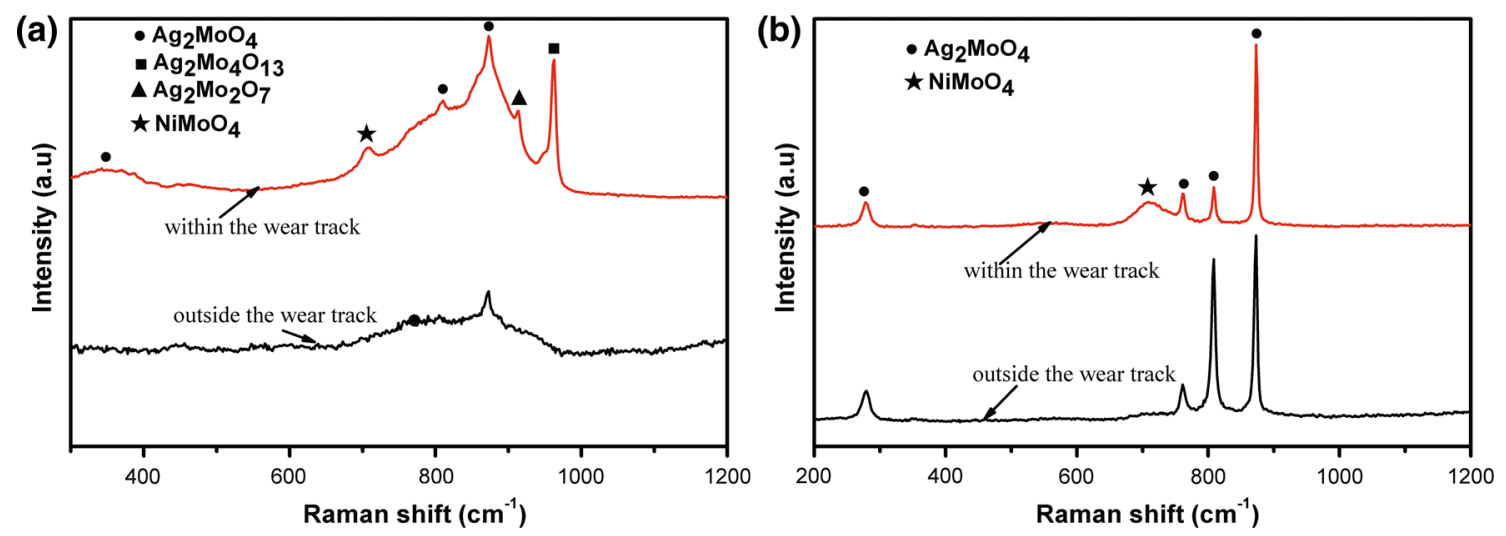

Fig. 10 Micro-Raman spectra of worn surfaces of NMA3 composite coatings tested at a $700{ }^{\circ} \mathrm{C}, \mathbf{b} 900{ }^{\circ} \mathrm{C}$

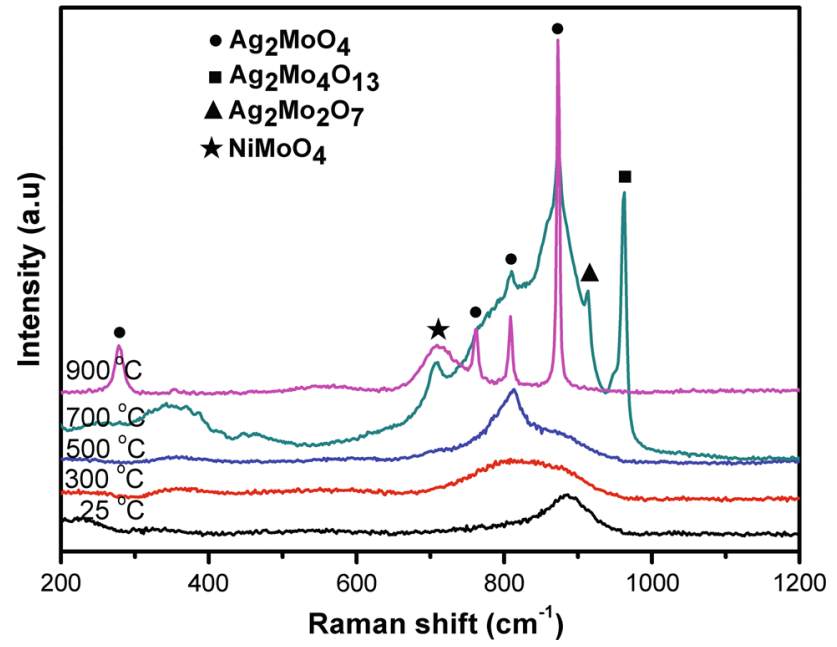

Fig. 11 Micro-Raman spectra of within the wear track of NMA3 composite coatings tested at different temperatures

At $900{ }^{\circ} \mathrm{C}$, the peaks of $\mathrm{Ag}_{2} \mathrm{Mo}_{4} \mathrm{O}_{13}$ and $\mathrm{Ag}_{2} \mathrm{Mo}_{2} \mathrm{O}_{7}$ disappear and the intensity of the $\mathrm{Ag}_{2} \mathrm{MoO}_{4}$ phase increases substantially.
The silver molybdate and nickel molybdate tribochemical reaction films were reproduced during rubbing test at high temperature and can lower friction coefficients and wear rates since the silver molybdate and nickel molybdate can be acted as a lubricating phase and then can effectively improve the tribological properties of composite coatings [27, 28]. The lubricating films could effectively reduce the direct contact between ball and disk and further improve the tribological properties of composite coatings [16].

\section{Conclusions}

1. The composite coatings are composed of $\mathrm{Ni}_{3} \mathrm{Al}, \mathrm{NiAl}$, $\mathrm{Ni}$ and $\mathrm{Y}_{2} \mathrm{O}_{3}$ phases. The $\mathrm{Y}_{2} \mathrm{O}_{3}$ phase is the oxide dispersion strengthening phase which can improve the strength of the composite coatings.

2. The addition of silver can effectively improve the tribological properties of composite coatings at a wide range of temperature. 
3. The rubbing process could form the nickel molybdate and promote the formation of the silver molybdate on the worn surface at high temperature.

4. The silver molybdate and nickel molybdate tribochemical reaction films could effectively improve the tribological properties of composite coatings at high temperature.

Acknowledgements This work was supported by the National Natural Science Foundation of China (Grant Nos. 51272207, 51471181 and 51575505).

\section{References}

[1] S. Hou, S. Zhu, T. Zhang, F. Wang, Appl. Surf. Sci. 324, 1 (2015)

[2] G. Bolelli, A. Candeli, L. Lusvarghi, A. Ravaux, K. Cazes, A. Denoirjean, S. Valette, C. Chazelas, E. Meillot, L. Bianchi, Wear 344-345, 69 (2015)

[3] S.B. Mishra, K. Chandra, S. Prakash, Surf. Coat. Technol. 216, 23 (2013)

[4] C. Guo, W. Wang, Y. Cheng, S. Zhu, F. Wang, Corros. Sci. 94, $122(2015)$

[5] H.C. Zhao, Y.B. Ren, J.H. Dong, X.M. Fan, K. Yang, Acta Metall. Sin. (Engl. Lett.) 29, 217 (2016)

[6] B. Li, Y. Gao, J. Jia, M. Han, H. Guo, W. Wang, J. Alloys Compd. 686, 503 (2016)

[7] W.Z. Yang, W.M. Huang, Z.F. Wang, F.J. Shang, W. Huang, B.Y. Zhang, Acta Metall. Sin. (Engl. Lett.) 29, 707 (2016)

[8] Z. Dai, G. Wang, L. Liu, Y. Hou, Y. Wei, Z. Zhang, Compos. Sci. Technol. 136, 1 (2016)

[9] L. Kong, Q. Bi, M. Niu, S. Zhu, J. Yang, W. Liu, Tribol. Int. 64, 53 (2013)

[10] S.M. Aouadi, Y. Paudel, W.J. Simonson, Q. Ge, P. Kohli, C. Muratore, A.A. Voevodin, Surf. Coat. Technol. 203, 1304 (2009)
[11] C. Liu, L. Chen, J. Zhou, H. Zhou, J. Chen, Appl. Surf. Sci. 300, 111 (2014)

[12] L. Kong, S. Zhu, Q. Bi, Z. Qiao, J. Yang, W. Liu, Ceram. Int. 40, 10787 (2014)

[13] J. Chen, J. Li, D. Xiong, Y. He, Y. Ji, Y. Qin, Appl. Surf. Sci. 361, 49 (2016)

[14] E. Liu, Y. Gao, J. Jia, Y. Bai, Tribol. Lett. 50, 313 (2013)

[15] J. Yang, Y. Zhang, X. Zhao, Y. An, H. Zhou, J. Chen, H. Guoliang, Tribol. Int. 90, 96 (2015)

[16] E.Y. Liu, W.Z. Wang, Y.M. Gao, J.H. Jia, Tribol. Int. 57, 235 (2013)

[17] F. Okumu, M. Matoetoe, Acta Metall. Sin. (Engl. Lett.) 29, 320 (2016)

[18] N. Ning, C. Miao, H. Zou, Q. Shao, S. Wang, L. Zhang, M. Tian, Compos. Sci. Technol. 136, 46 (2016)

[19] Y. An, J. Chen, G. Hou, X. Zhao, H. Zhou, J. Chen, F. Yan, Tribol. Lett. 58, 34 (2015)

[20] S.M. Aouadi, D.P. Singh, D.S. Stone, K. Polychronopoulou, F. Nahif, C. Rebholz, C. Muratore, A.A. Voevodin, Acta Mater. 58, $5326(2010)$

[21] J. Chen, G. Hou, J. Chen, Y. An, H. Zhou, X. Zhao, J. Yang, Appl. Surf. Sci. 261, 584 (2012)

[22] L. Kong, S. Zhu, Z. Qiao, J. Yang, Q. Bi, W. Liu, Tribol. Int. 78, 7 (2014)

[23] C. Muratore, A.A. Voevodin, J.J. Hu, J.S. Zabinski, Tribol. Lett. 24, 201 (2006)

[24] D.V. Shtansky, A.V. Bondarev, P.V. Kiryukhantsev-Korneev, T.C. Rojas, V. Godinho, A. Fernández, Appl. Surf. Sci. 273, 408 (2013)

[25] J. Chen, Y. An, J. Yang, X. Zhao, F. Yan, H. Zhou, J. Chen, Surf. Coat. Technol. 235, 521 (2013)

[26] C. Dellacorte, Edmonds, NASA PS400: a new high temperature solid lubricant coating for high temperature wear applications (National Aeronautics and Space Administration, Glenn Research Center, Washington, 2009)

[27] E.Y. Liu, W.Z. Wang, Y.M. Gao, J.H. Jia, Tribol. Lett. 47, 21 (2012)

[28] B. Li, J. Jia, Y. Gao, M. Han, W. Wang, Tribol. Int. 109, 563 (2017) 